\title{
TACNA EN LA COYUNTURA DE 1929-1934
}

\author{
TACNA AT THE JUNCTURE OF 1929-1934
}

\author{
Oscar Panty Neyra
}

\begin{abstract}
RESUMEN
Un estudio de coyuntura, como la focalizada entre los años 1929-1934, nos lleva a comprender las condiciones adversas en que ocurrió la Reincorporación de Tacna a la heredad nacional, después de casi cincuenta años de sojuzgamiento bajo administración chilena. El Perú, país periférico del sistema capitalista mundial, vivía una crisis generalizada en todo orden de cosas. Tacna reincorporada reproduce las características del sistema jurídico político administrativo centralista y a la vez dependiente de los intereses del gran capital norteamericano; por lo que las promesas de su reivindicación, en mérito a su fidelidad nacional, fueron largamente postergadas. Este trabajo destaca las alternativas aprista y socialista propagandizadas en la coyuntura por la superación de la crisis, la modernización y transformación del estado y la sociedad.
\end{abstract}

Palabras claves: Coyuntura, crisis nacional, modernidad, modernización, reincorporación.

\begin{abstract}
A study juncture dated among 1929-1934, takes us to understand the different conditions when the reincorporation of Tacna to the national heritage after nearly fifty years of sufferring uinder the chilean administration. Perú surrounding country of the worldy capitalist system, lived a generalized crises in nearly every order of things. Tacna reincorporated reproduces the characteristics of the juridical politic administrative centralist system, and depending at the same time on the interests of the American power, because the promises if its reivindication dued to its national fidelity were largely past poned. This work outstands the apristas and socialist alternatives propagandized to overcome the crises. The modernity and transformation of the state and the society.
\end{abstract}

Key Words: Juncture, crises national, modernity, modernization, reincorporation.

\footnotetext{
${ }^{1}$ Universidad Nacional Jorge Basadre Grohmann. Tacna-Perú. E-mail: opanty@hotmail.com
} 


\section{INTRODUCCIÓN}

La tarde del miércoles 29 de agosto del año 1929, Tacna reincorporada, el pueblo con su territorio, vivió el júbilo del fin de casi cincuenta años de lucha y resistencia contra la administración chilena de ocupación, producto de la guerra de 1879. Entonces, propios y extraños creyeron ver que llegaba la oportunidad histórica del reconocimiento nacional a la fortaleza de su identidad, puesta a las más duras pruebas; en tanto el gobierno central disponía el restablecimiento del orden jurídico-políticoadministrativo, además que prometía obras en la perspectiva de la reivindicación tacneña.

Un estudio general del curso de los acontecimientos durante la coyuntura de 1929-1934 y después de ella, permite distinguir una temprana desatención gubernamental a Tacna y una larga postergación de sus reivindicaciones. Sus consecuencias frustrantes y distorsionadoras para el desarrollo de Tacna y la región se han proyectado hasta la actualidad.

El presente trabajo de análisis coyunturalestructural se justifica desde el punto de vista teórico científico debido a que contribuye al conocimiento de una coyuntura poco investigada, y porque los trabajos realizados inciden mayormente en la Reincorporación de Tacna - momento inicial de esta coyuntura-, destacando los actos preparativos conducentes a la restauración de instituciones y autoridades, además de los protocolos concurrentes a la "entrega de Tacna". Por nuestra parte se trata de ampliar el conocimiento de la coyuntura respecto a las condiciones económicas, sociales, políticas e ideológicas en que se produjo la reincorporación; lo que nos posibilita comprender la postergación de las reivindicaciones tacneñas más sentidas.

Guían el desarrollo de nuestro trabajo, los objetivos que a continuación se formulan:

1. Precisar los caracteres generales de la sociedad peruana al momento de la Reincorporación de Tacna a la heredad nacional.

2. Determinar el significado de la Reincorporación de Tacna.

3. Identificar las manifestaciones de la crisis económica en Tacna, durante la coyuntura de 1929-1934.
4. Comparar las alternativas ideológicas socialista, socialdemócrata y fascistizante impulsadas por los partidos políticos con presencia nacional, su influencia en los gremios y en la práctica educativa de la coyuntura en Tacna.

5. Identificar los indicadores de modernidad y modernización en Tacna a través de la actividad periodística de la coyuntura.

\section{I \\ EL PERÚ AL MOMENTO DE LA REINCORPORACIÓN DE TACNA VISIÓN DE CONTEXTO}

Hacia el año 1929, el Perú aparece en perspectiva internacional como un país atrasado y dependiente en el orden capitalista bajo hegemonía norteamericana, en condición similar a los otros países latinoamericanos.

En 1929 la base económica de la sociedad peruana presentaba caracteres feudales en el agro andino; si bien ya asomaban los caracteres capitalistas en el agro costeño, en la explotación minero-petrolera y las manufacturas, en el transporte y el comercio. El arrollador capitalismo industrial monopólico norteamericano, que desde inicios del siglo desplazaba exitosamente de los mercados de la región al capitalismo británico, exige, en ciertos casos, la modernización de las economías nativas precapitalistas; asimismo, en otros casos, opta por el control directo de la producción mediante la introducción de las economías de enclave -"explotación minera-Cerro de Pasco y petrolera-La Brea y Pariñas, principalmente-", todo esto consolidando en nuestro país la orientación del desarrollo económico en los parámetros del modelo primario exportador. (Panty, O. 2001, p.11)

La observación a este proceso nos permite entender el contexto nacional en el cual se reincorpora Tacna, sus condiciones materiales de existencia, las posibilidades y las limitaciones para su desarrollo en general con un régimen político en crisis, la dictadura leguiista, y una economía sujeta a los dictados del gran capital norteamericano. 
Por el tratado de límites del 3 de junio de 1929 entre Perú y Chile, se puso término a la oprobiosa situación de "Tacna ocupada", aquella parte de territorio de la provincia de Tacna ubicada al sur del río Sama que durante casi 50 años permaneció bajo administración chilena, junto con la provincia de Arica, como consecuencia de la guerra de 1879 . Tacna venía de experimentar una situación de estancamiento bajo la administración chilena. Ya el diario peruano La Voz del Sur, en sus ediciones de setiembre y octubre de 1925, había hecho una reseña de la dramática situación de la economía chilena comparada con la peruana, particularizando la situación de postergación de Tacna y Arica. La misma prensa chilena llegó a manifestar que la administración de Tacna constituía un gasto oneroso para el fisco del país del sur.

La Reincorporación de Tacna al Estado peruano se produce en las condiciones de país atrasado, donde la modernización capitalista, incipiente pero progresiva, se yuxtapone a formas precapitalistas con fuerte sujeción al capital norteamericano. Gobernaba el país el presidente Augusto B. Leguía, gobierno del oncenio que hipotecó al Perú con diez grandes empréstitos de la banca norteamericana y que en 1929 ya se ubicaba al borde del colapso por la crisis del sistema; gobierno cuya política económica primario exportadora era radicalmente cuestionada por las alternativas socialista y aprista, las cuales iban ganando aceptación en las clases productoras.

En el documento denominado "Acta de Entrega de Tacna al Perú -1929" se registra que en la ciudad de Tacna, el día miércoles 28 de agosto, a las dos de la tarde, el delegado de Chile, don Gonzalo Robles, siguiendo las instrucciones de su gobierno "procedia a entregar al Peri, representado por la delegación que presidia el Doctor Rada y Gamio, la ciudad de Tacna junto con todos los territorios que quedan al norte de la línea de frontera establecida en el artículo segundo del Tratado chileno-peruano del 3 de junio...", lo que fue aceptado y recibido por la delegación peruana. El "Acta de entrega" fue firmada por los delegados de Perú y Chile en el marco de la ejecución del tratado en referencia, en el inmueble Casa de la Jurídica; local que por largos años ha sido residencia de los prefectos y que actualmente es sede del Archivo Regional de Tacna.
Sobre el mismo día de la Reincorporación de Tacna, el bisemanario tacneño La Patria registra una alocución del presidente Leguía en el Palacio de la Exposición ante 3000 mujeres de Lima. Entonces el presidente decía que su gobierno dotaría a Tacna de todo "cuanto requiera la vida moderna en las grandes ciudades [...]. Tacna redimida es la mejor ofrenda que mi patriotismo puede hacer al Perú". Así los ofrecimientos del gobernante fueron la construcción de carreteras y escuelas, el fomento de irrigaciones y el impulso a la industria y al comercio, obras que no llegaría a concretar porque sobre él ya pendía el golpe de Estado.

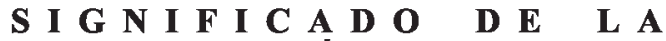 REINCORPORACIÓN}

Conviene destacar que para regular su funcionamiento cada vez más complejo en el tiempo, toda sociedad genera instituciones y dispositivos legales que constituyen su estructura jurídico-político-administrativa. Dicha estructura -que no es otra cosa que el Estado- bien sirve para reproducir las condiciones económicas, políticas e ideológicas del orden imperante; bien se pone al servicio de un nuevo orden, cuando en ella se producen transformaciones fundamentales en correlación con las transformaciones que también deben ocurrir en la estructura económica, base del edificio social.

Para implementar la Reincorporación de Tacna al Estado peruano, el gobierno del oncenio leguiista dispuso, dentro del marco de la Ley $\mathrm{N}^{\circ} 6630$, la corrección y reforzamiento de la estructura jurídico-política departamental como parte de la estructura jurídico-política del país, empezando por el restablecimiento de la capital y prefectura del departamento. Obviamente siguiendo los lineamientos centralistas de la Constitución Política vigente desde 1920, con las enmiendas de los años 1924 y 1929 que dieron preeminencia al poder ejecutivo.

La capital del departamento, ubicada en la villa Locumba (sector "Tacna libre") durante la ocupación chilena, fue trasladada a la ciudad de Tacna por decreto del presidente Leguía; lo que se ejecutó el 28 de agosto de 1929. Su tenor resolutivo reza escuetamente: "Trasládase a la ciudad de Tacna, la capital del departamento del mismo nombre". 
Así reconstituido el departamento, su demarcación política territorial habrá de comprender dos provincias: Tacna y Tarata. La primera, con seis distritos (Tacna, Calana, Pachía, Sama, Locumba e Ilabaya); la segunda provincia, con siete distritos (Tarata, Candarave, Curibaya, Estique, Huanuara, Tarucachi y Ticaco).

El Estado, con un poder ejecutivo centralista, se reprodujo en Tacna restableciendo la prefectura departamental, las subprefecturas provinciales y las gobernaciones distritales, con los cargos de confianza para los más allegados al régimen. Los órganos sectoriales aparecieron limitados en sus funciones organizativo-administrativas y en el poder de decisiones e iniciativas; ello por la fuerte dependencia jerarquizada del gobierno central, las limitaciones en la disponibilidad de los recursos presupuestales, la carencia de personal calificado y la falta de coordinación intersectorial. Situación que habría de prolongarse durante la coyuntura agravada por la crisis y sobre la cual la prensa, bajo las influencias ideológicas del cambio social, promocionó la propuesta de descentralismo entre la modernización y la transformación del Estado como alternativa de solución.

Se restituyó también la Corte Superior de Justicia, pero de manera accidentada. Leguía, mediante decreto del 9 de agosto, ordenó: "Reorganizase en la ciudad de Tacna una Corte Superior con jurisdicción sobre el departamento del mismo nombre y la provincia litoral de Moquegua". Meses más tarde, la Corte Superior fue retirada de Tacna e integrada a la Corte Superior de Arequipa, por orden de la Junta de Gobierno presidida por el comandante Sánchez Cerro; reinstalada, después, por decreto de la Junta de Gobierno presidida por David Samanez Ocampo, el 25 de marzo de 1931.

Asimismo el ejército, con el regimiento Húsares de Junín procedente de Arequipa, y el servicio nacional de policía fueron instalados de manera puntual, como lo que históricamente han constituido junto con el aparato administrativo: las columnas fundamentales del Estado. El coronel Miguel Andrés de la Misión Española de Policía fue el encargado de la organización del mencionado servicio en Tacna.
Pero en lo que corresponde a la representación en el poder legislativo, el pueblo de Tacna fue relegado desde el momento de su reincorporación. Los congresistas constituyentes Arce y Neuhaus elegidos por Tacna dos años después, en los comicios del 11 de octubre de 1931, fueron tempranamente desaforados y enviados al exilio por el régimen de Sánchez Cerro; quien no pudo sostener la práctica democrática en el debate parlamentario. Tacna fue privada de representación ante el Congreso de la República por espacio de siete años.

\section{II
LA CRISIS ECONÓMICA EN LA COYUNTURA DE 1929-1934

Importantes estudios sobre el desarrollo de la economía peruana y latinoamericana han coincidido en destacar al sector exportador como su motor fundamental. El conocimiento histórico y la evidencia empírica han corroborado esta aseveración. Los periodos de crecimiento de la producción nacional han ocurrido relacionados con los de bonanza de las exportaciones; inversamente los periodos de crisis en el sector exportador han sido seguidos por situaciones de crisis internas. El caso es que las exportaciones han sido y siguen siendo productos primarios, mayormente mineros y bajo conducción de corporaciones transnacionales; lo que ya supone limitaciones para el beneficio nacional, más aún, descapitalización. Con tales consideraciones, veamos cómo la crisis económica de 1929-34 afectó al sector nacional primario exportador:

Cuando en setiembre de 1929 se inició la gran depresión capitalista de los Estados Unidos, reduciendo sensiblemente su producción, por tanto las importaciones de materias primas, nuestro país vio seriamente comprometido su comercio exterior, el sector más rentable; el que no solo captaba divisas, sino que también canalizaba las inversiones extranjeras. Los productos minero-petroleros fueron los más afectados. El cobre descendió de 61,186 en 1929 a 24,835 toneladas en 1932 , con la correspondiente contracción de sus precios; la explotación de 
petróleo crudo disminuyó de 77 millones de barriles en 1929 a 47 millones de barriles en 1932. Los productos agrícolas, como el algodón y el azúcar, si bien mantuvieron sus volúmenes de exportación, fueron drásticamente reducidos en sus precios particularmente el algodón que descendió en un $50 \%$. (Cotler, J. 1978, p. 227)

La reducción de las exportaciones afectó la captación de impuestos, disminuyendo los ingresos para el presupuesto nacional; además repercutió en la devaluación de la moneda nacional, la quiebra bancaria y la descapitalización del país: situaciones que se acentuaron aun en el presupuesto nacional. De 125836507 soles en 1929 (equivalentes a US \$50 334 544) el presupuesto disminuyó a 95430044 soles en 1933 (equivalente a US \$21 208454 ).

Una puntual descripción en apretada síntesis sobre el desempleo, la reducción de los ingresos y la contracción de la demanda por la crisis, es la que Julio Cotler nos alcanza en los términos siguientes:

Los enclaves mineros y agrícolas despidieron a más de la mitad de sus trabajadores y los salarios se redujeron en una proporción análoga. Los algodoneros suspendieron el enganche de cerca de 40,000 campesinos serranos que bajaban a apañar algodón a fin de complementar sus ingresos. En Lima el desempleo alcanzó casi a la cuarta parte de trabajadores. La reducción de los ingresos fiscales por la radical disminución de las entradas aduaneras y la suspensión de los préstamos norteamericanos, obligó al gobierno a paralizar las obras de mejoramiento urbano, lo que afectó al $70 \%$ de los obreros de la construcción. La reducción de la capacidad de compra motivó el despido del $12 \%$ de los trabajadores textiles. Los empleados del gobierno, cuyo número se había duplicado en el "Oncenio", se encontraron impagos. La ola de la bancarrota arrastró consigo a la entidad financiera de mayor importancia en el país, el Banco de Perú y Londres, deteriorando aún más la difícil situación económica. El desempleo y la comprensión de los ingresos urbanos, trajo consigo una brusca reducción de la demanda de alimentos que incidió sobre las rentas de los terratenientes e ingresos de los pequeños propietarios y comunidades indígenas tradicionales, proveedores de alimentos de los centros urbanos. (Cotler, J. 1978, p. 227).

La crisis económica agudizó la crisis política. La convulsa situación nacional se hizo inmanejable para el régimen del oncenio, por lo que este llegó a su fin con el golpe de Estado del 25 de agosto de 1930. Se formó una Junta Militar de Gobierno presidida por el comandante Luis Miguel Sánchez Cerro, bajo los auspicios de la derecha civilista, y que luego recibió el apoyo norteamericano (Misión Kemmerer) para enfrentar la crisis; sin embargo, la crisis nacional se agudizó aún más, y generó una maratónica sucesión de cuatro juntas de gobierno: E1 20 de febrero de 1931 se sublevó la guarnición militar de Arequipa contra Sánchez Cerro, proclamando como Presidente de una Junta Nacional de Gobierno al hacendado David Samanez Ocampo. En Lima, Sánchez Cerro entrega el poder al Presidente de la Corte Suprema de Justicia, Ricardo Leoncio Elías, quien pocos días después transfirió el mando al General Gustavo Jiménez como Presidente de una Junta Transitoria de Gobierno. Tras presuroso viaje, Samanez llegó a Lima y asumió la presidencia de la Junta Nacional de Gobierno del Perú, el 11 de marzo de 1931.

Samanez gobernó por espacio de nueve meses en un ambiente de intentos golpistas, conflictos laborales y descontento generalizado. En ese periodo convocó a elecciones generales, puso en vigencia un nuevo Estatuto electoral y fortaleció la autonomía del Jurado Nacional de Elecciones. Por recomendación de la Misión Kemmerer creó el Banco Central de Reserva del Perú, dispuso la ejecución de una ley de bancos y una nueva ley de reforma monetaria. Asimismo, estableció un Fondo Pro-Desocupados en ayuda a los más necesitados y víctimas de la crisis. 
Realizadas las elecciones, Samanez entregó el gobierno al Comandante Sánchez Cerro el 8 de diciembre de 1931, candidato del urrismo fascistizante, triunfante sobre su más cercano competidor, Víctor Raúl Haya de la Torre, de las filas del aprismo socialdemócrata. Pero la crisis continuó en toda su extensión.

\section{LACRISIS ECONÓMICA EN TACNA}

No bien transcurrían cincuenta y seis días de la Reincorporación de Tacna, cuando el anuncio de la crisis económica capitalista hizo remecer los cimientos de su incipiente economía. La fracción empresarial de origen italiano, que ocupó el espacio dejado por la fracción de origen británico, como consecuencia de la guerra, se vio perturbada en el reordenamiento de sus actividades comerciales. La banca nacional que sustituyó a la chilena en Tacna fue seriamente impactada por la crisis. La sucursal del Banco del Perú y Londres en Tacna terminaría, poco después, cerrando sus puertas al declararse en quiebra la sede principal de Lima. El gobierno central aún no concluía con la reinstalación del aparato jurídico administrativo para consolidar la reinserción de Tacna y, de alguna manera, coadyuvar a su desarrollo en el marco de la modernización capitalista bajo hegemonía norteamericana.

Fueron tiempos sumamente difíciles. Testimonios registrados por la prensa nos aproximan a la dramática realidad. En las ediciones de setiembre de 1929 el bisemanario La Patria, antes de la crisis, presenta auspiciosos avisos de las sucursales del Banco Italiano-Lima y el Banco del Perú y Londres, con sedes centrales en Lima, ofreciendo todo tipo de operaciones bancarias. El Banco Italiano, convertido después en Banco de Crédito, aparece como el más sólido, con capital pagado de LP 8000000000 00 y reservas de LP $1,114612^{\circ} .43$; su sección ahorros publicita el pago de interés del $6 \%$ anual.

Hasta el 15 de enero de 1931 el diario La Nación propagandiza a la sucursal del Banco del Perú y Londres. Ese mismo día, un comunicado de la oficina local anuncia al público que los saldos de sus libretas serán transferidos a la Caja Nacional de Ahorro y que los pagos se realizarán en la oficina del Banco Italiano. Este era el inicio formal de la extinción del banco. Luego, el 27 de febrero la Superintendencia de Bancos declara el estado de quiebra del Banco en referencia, consecuentemente decreta su liquidación.

Cabe destacar que en este contexto de crisis económica que devino en crisis social generalizada, las reivindicaciones anunciadas y prometidas para Tacna reincorporada se postergaron por largo tiempo. Ya en su edición del 12 de febrero de 1931, el diario La Nación editorializa:

A pesar de que el contraste era palpable, Tacna vivió de la esperanza de que el gobierno central se preocuparía alguna vez de ella (...). Pero esa vez no llegó, no ha llegado hasta ahora. El problema de Tacna es en el fondo un problema de dignidad nacional. Un problema de desesperanza de un pueblo que clamó cincuenta años para volver.

No obstante, por sobre todo sentimiento negativo y frustrante, el artículo editorial sugiere al gobierno de turno compensar a Tacna con un régimen transitorio excepcional en lo legislativo y económico.

En sus ediciones del 20 y 21 de febrero, el diario pone de manifiesto la profunda preocupación social por el alza de los precios de los productos de primera necesidad, además por la escasez de moneda fraccionaria. Después, otros artículos periodísticos describirán la crisis de la agricultura y el comercio, y plantearán como alternativa priorizar la construcción de carreteras y el desarrollo de la agricultura de frutales.

Bajo el título Tacna, la Esparta de América, el Dr. Víctor Larco Herrera escribe un artículo en el diario La Nación sobre las exportaciones de Tacna a Chile (10-11-1931), precisando que antes de la crisis llegaban hasta $490 \mathrm{Tm}$, y que en el año 1931 se reducen a $240 \mathrm{Tm}$. Indica también que la exportación de reses en 1931 era nula. De este artículo, elaborado con información de la Estación Experimental de Tacna, glosamos la siguiente tabla sobre exportación de productos agrícolas a escala menor en plena crisis: 
Tabla 1

EXPORTACIÓN DE PRODUCTOS AGRÍCOLAS DE TACNA AL PUERTO DE ARICA ENTRE 1929-1930 EN SOLES DE LA ÉPOCA.

\begin{tabular}{lc}
\hline \multicolumn{1}{c}{ Productos } & Valor S/. \\
\hline Verduras, legumbres, frutas & 720.000 \\
Papa, camote & 28,000 \\
Chancaca, melcocha & 3,500 \\
Leche fresca & 800 \\
Huevos & 12,000 \\
Ganado & 224,000 \\
Aves & 6,000 \\
\hline TOTAL & $\mathbf{9 9 3 , 0 0 0}$ \\
\hline
\end{tabular}

Fuente: Diario La Nación. Tacna, 10 de noviembre de 1931. Artículo Tacna, la Esparta de América del Dr. Víctor Larco Herrera.

Respecto a la producción industrial, el mismo diario La Nación nos presenta un panorama de economía incipiente, llegando a la expresión categórica que en Tacna "no hay fábrica ni industrias de importancia" (1-12-1931). Por su parte, el diario La Verdad se encarga de publicar las listas oficiales de contribuyentes (ver Tabla 2), donde se pone de manifiesto una débil industria de bienes de consumo, principalmente gaseosas, seguidas de los fideos y velas.

Tabla 2

CONTRIBUYENTES DE LA INDUSTRLA TACNEÑA - AÑO 1932.

\begin{tabular}{|c|c|c|}
\hline CONTRIBUYENTES & CLASE DE INDUSTRIA & $\begin{array}{l}\text { CONTRIB. ANUAL } \\
\text { S } / .\end{array}$ \\
\hline Bacigalupo Marcel & Fab. fideos, gaseosas, varios & 400.00 \\
\hline Bacigalupo P.y Cia. & Fábrica de fideos & 200.00 \\
\hline Alquiler Mac. & Fábrica de velas & 100.00 \\
\hline Córdova Manuel & Molienda de canfas & 25.00 \\
\hline Coda Humberto & Fábrica de aguas gaseosas & 50.00 \\
\hline Barrios Felipe & Fábrica de aguas gaseosas & 50.00 \\
\hline Viacava Tomas & Fábrica de aguas gaseosas & 52.00 \\
\hline
\end{tabular}

Fuente: Matrícula de Contribución Comercial e Industrial de Tacna Afro 1932.

Consecuencia de la crisis fue la desocupación que se acentuó en la ciudad de Tacna. En diciembre de 1531 había 400 desocupados en el distrito de Tacna, registrados por la Junta Pro-desocupados de Tacna (La Nación 4-12-31); tales desocupados representaban el 12\% de la población masculina de 3300 residentes.

El Censo de población de Tacna de 1935, ejecutado por la Prefectura con los auspicios de la Junta Pro- Desocupados, reveló la existencia de 302 desocupados, lo que representa el $8.5 \%$ de la población masculina de 3550 residentes en la ciudad de Tacna, zonas aledañas y localidades de Calana y Pachía.

Tabla 3

DESOCUPADOS EN TACNA DURANTE 1935.

\begin{tabular}{lc|cc}
\hline Distrito & Zonas urbanas & Zonas rurales & Total \\
\hline Tacna & 224 & 44 & 268 \\
Calana & 12 & 13 & 25 \\
Pachía & 3 & 6 & 9 \\
& & & 302 \\
\hline Totales & 239 & 63 &
\end{tabular}

Fuente. Censo de Población de Tacna-Calana-Pachía. 1935.

Para enfrentar la crisis y la desocupación en Tacna, la Junta nacional de Gobierno, presidida por David Samanez Ocampo, ordenó por D.L. del 29 de mayo de 1931 el destino de 300,000 soles de la liquidación de la Caja Nacional de Ahorros. De los mencionados 300,000 soles, el 10 de junio decretó separar y empozar 50,000 soles en una cuenta especial de la Caja Depósitos y Consignaciones, denominada "Vivero Nacional de Tacna", para fomentar la industria agrícola a cargo de la Estación Agronómica. Por Resolución del 1 de junio se destinó 150,000 soles para mejoramiento de canales 
de regadío. Los 100,000 soles restantes mediante decreto del 23 de julio pasaron a la cuenta especial "Caminos en el departamento de Tacna".

El Comité Pro-desocupados, creado en julio de 1931, impulsó algunas obras para dar trabajo temporal a los desocupados, empezando con la reparación de la carretera TacnaTarata. Pero luego los trágicos años de guerra interna, 1932-1934 (gobiernos de Sánchez Cerro y Benavides) postergaron el desarrollo material de Tacna. En 1934, durante el gobierno del general Benavides, la atención a Tacna se redujo a una partida de 10,0000 soles para instalación de agua potable. A Tarata solo se le destinó la cantidad de 4,600 soles.

\section{SITUACIÓN SOCIOPOLÍTICA}

Al culminar la década de los años 20 , la sociedad nacional presentaba en la cúspide de su estructura piramidal de clases una burguesía agroexportadora dominante sobre los demás grupos y clases, pero dependiente respecto a la gran burguesía imperialista. Contrariamente, en la base de la sociedad emergía el proletariado, incipiente aún, con sus fracciones de petroleros, mineros, textiles y trabajadores agroindustriales; además existía el campesinado pobre conformado por pequeños propietarios minifundistas, comuneros y campesinos sin tierra, siendo estos últimos una mayoría de aparceros, yanaconas y "enganchados". Finalmente, completando la pirámide social, se diversificaban las capas medias o pequeñas burguesías de artesanos, comerciantes, empleados estatales y particulares, profesionales de todas las ramas, intelectuales y estudiantes, grupos relativamente permeables a las influencias ideológicas de las clases fundamentales, destacando, en ciertas coyunturas, las actuaciones descollantes de intelectuales y estudiantes indignados por las injusticias y las manipulaciones de los grupos de poder, como ocurrió en las luchas por la jornada de ocho horas de trabajo en 1929, o la movilización contra la consagración del Perú al Corazón de Jesús en 1923.

Es evidente que al interior de la pirámide social de la época, la estructura de clases de Tacna, segmento de la estructura nacional, tuvo que reproducir los caracteres generales de la estructura en referencia, con los rasgos propios de una estructura local con desarrollo incipiente basado en relaciones económicas capitalistas, también incipientes, con rezagos serviles. Es decir, pequeños grupos poco diversificados de trabajadores agrícolas entre jornaleros eventuales, enganchados, aparceros y comuneros; además de grupos de artesanos, empleados, pequeños propietarios y comerciantes, sobre los que se erigía una fracción de medianos hacendados de los valles de Tacna, Sama y Locumba, y otra fracción de comerciantes intermediarios descendientes de inmigrantes europeos, particularmente italianos residentes en la ciudad de Tacna. Estos últimos, de grupo insignificante y marginal antes de la guerra, se encumbraron rápidamente durante la ocupación colaborando con los invasores y con su aparato administrativo.

Es justo reconocer que al promediar la década de los años 20 fueron Víctor Raúl Haya de la Torre y José Carlos Mariátegui quienes aportaron al estudio de las clases sociales en el Perú, su estructura y dinámica; apoyados en presupuestos ideológicos y metodológicos tomados del marxismo. Ambos coincidieron en sostener que las clases sociales se estructuran y desarrollan a partir de determinadas relaciones de producción, de condiciones materiales de vida y de intereses de grupo; de igual forma, se desempeñan como fuerzas a favor o en contra de la modernización y cambio de la sociedad, de acuerdo a sus niveles de conciencia, organización y lucha. Sin embargo, discreparon en determinar las potencialidades de las clases y en la asignación de los roles a desempeñar por cada clase y fracción de clase. Claro está que dichas discrepancias guardaban correspondencia con sus proyectos alternativos de Sociedad y Estado:Aprismo y Socialismo.

\section{TENDENCIAS Y ORGANIZACIONES POLÍTICAS}

Acontecimientos como la revolución mexicana, la revolución soviética, el movimiento fascista italiano y la reforma universitaria generada en Córdova (Argentina), sumados a la modernización y crisis capitalista que se vivía en Perú y Latinoamérica, fueron condicionantes de la 
génesis y desarrollo de tres tendencias políticas en el país: socialdemócrata, socialista y fascistizante, con la correspondiente fundación y proselitismo de sus respectivas organizaciones partidarias.

\section{La Tendencia Social Demócrata}

La socialdemocracia en la versión aprista surgió en 1923 con las jornadas estudiantiles del 23 de mayo, en contra de la pretensión de la dictadura leguiista de consagrar el Perú al Corazón de Jesús; toma dimensión continental el 7 de mayo de 1924, cuando Haya en México, junto con otros peruanos exiliados, da por fundado el movimiento Alianza Popular Revolucionaria Americana (APRA). Después, tras el derrocamiento de Leguía por Sánchez Cerro, se constituyó en Lima el Partido Aprista Peruano, el 21 de setiembre de 1930. En Tacna se instaló el primer comité departamental en mayo de 1931, con miras a participar en el proceso electoral convocado por la Junta de Gobierno presidida por Samanez Ocampo.

Haya delineó la concepción aprista con su obra fundamental El antiimperialismo y el Apra, terminada de escribir en 1928, pero editada en 1936; si bien publicó otros trabajos antes y durante la coyuntura que nos ocupa: Por la emancipación de América Latina (1927), Ideario y acción aprista (1930), El plan del aprismo (1932), Política Aprista (1933).

Según Haya (1986), en el Perú y Latinoamérica prevalecía una sociedad con relaciones feudales, donde un grupo de gamonales ejercía el poder económico y político, manteniendo una gran masa indígena en condiciones serviles, carente de ciudadanía; la industria era incipiente, por lo que la burguesía estaba en sus inicios, mientras que el proletariado, aún joven aparecía en reducido número. Las clases medias emergentes completaban la estructura social.

Dada la caracterización social en referencia, en la óptica aprista no estaba la revolución socialista, sino una revolución social que emprendiese la construcción de una sociedad de transición, con un estado antiimperialista, en la que una política de nacionalizaciones (de grandes empresas mineras y petroleras) llevaría a la consolidación de una economía estatal, lo que potenciaría al Estado para enfrentar al imperialismo o negociar con él en otras condiciones. Al lado del sector estatal se organizaría el sector cooperativista (de empresas agro-industriales) y el sector de empresa privada de pequeñas y medianas industrias. $Y_{\text {¿cómo se construiría el }}$ Estado antiimperialista? Mediante la alianza de las tres clases oprimidas por el imperialismo: el campesinado, el proletariado y las clases medias. De estas últimas, sus intelectuales, técnicos y profesionales asumirían el rol dirigente.

\section{La Tendencia Socialista}

La labor ideológica de Mariátegui, inmediatamente después de su retorno de Europa, en marzo de 1923, marca la definición de la tendencia socialista en el Perú. El mismo Mariátegui (1975) se encargaría de deslindar su labor periodística e intelectual pre-socialista hasta su partida a Europa en 1919, de la labor comprometida con el socialismo marxista en Europa, desde donde concierta, según expresiones propias, "con algunos peruanos para la acción socialista"; lo que implicaba múltiples tareas de investigación, teorización, organización sindical y política, producción ideológica y proselitismo, entre 1923 y 1928.

El caso es que el 7 de octubre de 1928 se fundó el Partido Socialista del Perú, cuya declaración de principios, redactada por Mariátegui, expresa de modo categórico:

La ideología que adoptamos es la del marxismo-leninismo militante y revolucionario, doctrina que aceptamos en todos sus aspectos: filosófico, político y económico-social. Los métodos que sostenemos y propugnamos son los del socialismo revolucionario y ortodoxo. No solo rechazamos, sino que combatimos en todas sus formas los métodos y las tendencias de la socialdemocracia y de la II Internacional.

Estas últimas expresiones, en buena cuenta, significaban una declaratoria de guerra al aprismo de la socialdemocracia en el Perú y Latinoamérica. 
La tendencia socialista tuvo un desarrollo relativo en los sectores laborales del País, particularmente entre los obreros que avanzaban de la posición anarco-sindicalista a la posición sindical-clasista.

Podemos afirmar que en Tacna no hubo organización política socialista alguna, ni siquiera un grupo difusor de las ideas mariateguistas. No obstante, aunque parezca paradójico, fueron algunos apristas quienes se encargaron de difundir eventual y fragmentariamente el pensamiento mariateguista, a través del diario La Nación. Temas referidos a la revolución, el comportamiento de los intelectuales, el regionalismo y el centralismo, probablemente fueron tomados de las obras La escena contemporánea y Siete Ensayos, o de las revistas limeñas Variedades y Mundial que en 1925 y 1926, respectivamente, adelantaron la publicación de los contenidos en referencia.

\section{La Tendencia Fascistizante}

El fascismo fue un movimiento político de orientación totalitaria y anticomunista, surgido y desarrollado en Europa inmediatamente después de la Primera Guerra Mundial, como reacción ante el avance partidario de la izquierda marxista. Tuvo su primera expresión en Italia, con Mussolini; luego en Alemania, con Hitler: países donde grupos de ex-combatientes, desocupados y capas medias formaron la base social del movimiento, el mismo que llegó al poder estableciendo una férrea dictadura al servicio del gran capital bajo los principios de la supremacía del Estado, la disciplina y la jerarquía de los individuos.

En el Perú se genera una tendencia fascistizante con el gobierno de Sánchez Cerro, como reacción contra el avance de los movimientos populares, particularmente contra el APRA, principal movimiento de masas que sostenía una prédica antioligárquica y antiimperialista en la coyuntura que nos ocupa. En Tacna la tendencia fascistizante fue impulsada por el Comité Departamental del Partido Unión Revolucionaria (UR) y llegó a ser promocionada por el diario La Nación cuando los periodistas apristas dieron paso a un director de esa tendencia contraria entre el 15 de agosto y el 18 de setiembre de
1931. Después, entre 1932 y 1934, el diario La Verdad se desempeñó como órgano oficioso de la tendencia fascistizante.

Frente a las tendencias aprista y socialista de orientación internacionalista, que ponían en cuestión al orden tradicional y agitaban un programa de reformas de la sociedad y el Estado, el urrismo fascistizante con su lema "el Perú ante todo" irrumpe en el escenario político resaltando una orientación nacionalista de viejo cuño que respondía a los intereses del gamonalismo y la plutocracia, consecuentemente su propósito inmediato era restablecer y mantener el orden frente a la crisis y la beligerancia política. En este sentido, procedió a levantar un programa de emergencia con medidas de estabilidad monetaria, presupuestos balanceados, promoción a la inversión extranjera, descentralización administrativa, colonización de la selva.

En la dura confrontación electoral de 1931, el urrismo fascistizante resultó ganador a nivel nacional; sin embargo, en Tacna la victoria fue de la tendencia aprista con los dos representantes al Congreso Constituyente: Juan Arce Arnao y Gustavo Neuhaus.

Mencionemos aquí que del total de 145 congresistas, 27 fueron apristas quienes, desde el inicio del Congreso, presionaron al régimen con el planteamiento de políticas radicales para salir de la crisis y emprender el cambio de la sociedad peruana. Tales políticas fueron la moratoria del pago de la deuda externa, en tanto no se determinase la cuantía y legitimidad de los empréstitos suscritos por los gobiernos anteriores; la nacionalización de fuentes de riqueza, fomento de la minería y la agricultura bajo control del Estado, creación del Consejo económico nacional, nuevo régimen laboral, ciudadanía de la mujer y de los mayores de 18 años, reforma educativa empezando con la obligatoriedad y gratuidad de la enseñanza primaria bajo control del Estado.

Don Jorge Basadre en su monumental obra Historia de la República del Perú, ha registrado los proyectos de la representación aprista, de lo que extractamos lo siguiente: 
Los apristas llegaron a presentar entre otros los siguientes proyectos: ley de elecciones municipales; de revisión de los empréstitos y monopolios; de rebaja de alquileres; de estabilidad de empleo; de estabilidad de los obreros; de desocupados; de estudio integral del Presupuesto; de derogatoria de la ley de emergencia; sobre igualdad de los hijos legítimos e ilegítimos; voto calificado de la mujer; voto de los analfabetos; voto de los militares; voto de los mayores de 18 años; Consejo Económico Nacional; Congreso previo de investigaciones económicas; revisión del Tratado con Colombia(3); Censo General del Perú; Departamento de Estadística; laicización, obligatoriedad y gratuidad de la enseñanza primaria; en favor de los hijos y de las obras de José Carlos Mariátegui; declaración de que Manuel Gonzáles Prada fue hijo ilustre del Perú; cooperación al sostenimiento de la familia de Hermilio Valdizán; creación de un hogar-escuela con comida para los vendedores de periódicos; obligación de las empresas cinematográficas de dar trabajo a los músicos desocupados por causa del cine parlante; rebaja de las tarifas cobradas por las Empresas Eléctricas Asociadas entre Santa Beatriz y La Exposición; protección a los pequeños agricultores en la Provincia de Cañete; reducción de la cifra señalada en la Ley de Bancos para el monto del capital en las sucursales de los bancos en las capitales de departamento; creación de estaciones de telefonía inalámbrica en el departamento de Loreto; amnistía para las contribuciones de los pequeños mineros no cobradas en el segundo semestre de $1930 \mathrm{y}$ en el año de 1931 y rebaja de ellas; reforma educacional.

Un aviso publicado en La Tribuna del 24 de enero de 1932 señaló que la célula parlamentaria aprista estaba estudiando: un código del trabajo con legislación completa sobre los derechos del obrero y del empleado; una modificación total del régimen impo- sitivo con supresión de los impuestos indirectos e implantación de gravámenes sobre utilidad, la renta, etc.; la nacionalización de las fuentes de riqueza; una nueva organización de la Justicia; una nueva Ley de divorcio; y el fomento de la riqueza nacional auténtica mediante el apoyo a la minería y a la agricultura peruanas con el contralor del Estado para beneficio de trabajadores y empleados y del país en general. (Basadre, J. 2000, pp. 32183220)

Por toda respuesta a los planteamientos apristas -incapaz de sostener el debate doctrinario-el régimen fascistizante decretó la expulsión, encarcelamiento y destierro de la representación aprista que era minoría. Agentes policiales violentaron la majestad del Congreso Constituyente el 13 de febrero de 1932, hicieron escarnio de la inmunidad parlamentaria y tomaron presos a los diputados apristas para después enviarlos al exilio. El Congreso quedó mutilado y mediatizado en sus debates. No hubo reemplazantes. Tacna se vio privada de representación parlamentaria por espacio de siete años.

\section{ORGANIZACIONES GREMIALES}

Existe una relación directa entre el desarrollo de las fuerzas productivas y la aparición de los sindicatos. El hombre y los medios de trabajo constituyen las fuerzas productivas. El hombre es la principal fuerza de trabajo. Se desarrolla cuando perfecciona a los medios de trabajo con los cuales opera sobre los objetos de trabajo. El desarrollo de las fuerzas productivas al llegar a cierto nivel entra en contradicción con las relaciones de producción, en cuyo marco se desarrollaron y que en adelante pugnan por su modificación en cuanto ya no satisfacen a sus necesidades. Los sindicatos son una forma de organización y lucha de los trabajadores por mejores condiciones económicas, lo que implica la realización de modificaciones en las relaciones de producción.

En el Perú de la segunda mitad del siglo XIX, en el marco de cierto nivel de desarrollo capitalista urbano y con un régimen de abierta importación de productos manufacturados, surgieron las organizaciones mutualistas con fines asisten- 
cialistas en cuestiones económicas, sociales y culturales; un intento por aliviar las difíciles condiciones de vida de los trabajadores. En Tacna se formó la Sociedad deArtesanos y Auxilios Mutuos El Porvenir, el 26 de enero de 1873.

La guerra con Chile, 1879-1883, truncó el desarrollo del capitalismo en el país y afectó al mutualismo. Pero más adelante, con la llamada reconstrucción nacional, retornó ese desarrollo con los auspicios del capital inglés, seguido por el norteamericano. Se reorganizó el gremialismo transitando hacia el sindicalismo, al calor de las prédicas anarquistas. La explotación capitalista con el pago de bajos salarios, las jornadas laborales de 10,14 y 16 horas diarias, sin amparo legal, y el aumento del costo de vida por el incremento de las exportaciones e importaciones generaron las huelgas de tipógrafos, portuarios, textiles, panaderos, petroleros y jornaleros agrícolas. En 1918 se cohesionó el movimiento sindical en torno a la Federación Obrera local de Lima, priorizando la lucha por la jornada de ocho horas, cuyo triunfo se alcanzó el 15 de enero del año siguiente.

Durante la década del 20 al 30, el sindicalismo se extendió de la ciudad al campo; sin embargo, la crisis internacional que se avecinaba determinó la reducción de las operaciones en las empresas, con los consiguientes despidos de trabajadores.

Tacna reincorporada, con un incipiente desarrollo capitalista, aunque con el influjo de las nuevas corrientes ideológicas aprista y socialista que estimulan la organización sindical, habrá de experimentar la promoción de los primeros sindicatos de las actividades urbanas: educación y comercio. Aún bajo la inspiración mutualista, se fundó la Asociación de Maestros, el 10 de noviembre de 1929; sus promotores fueron los profesores David Mujica y Gerardo Lázaro de la sección primaria del Colegio Nacional de Varones y del Centro Escolar $N^{\circ} 995$, respectivamente.
No obstante, será dos años más tarde, 6 de julio, cuando el gremio de profesores se funde como Asociación Departamental de Maestros Primarios de Tacna, en momentos que la crisis económica se agudiza. La prensa de aquellos días informa que al Colegio Nacional de Varones se le adeudan subvenciones fiscales correspondientes a los meses de mayo y junio. Asimismo informa sobre la creación del Comité Pro desocupados a nivel departamental.

Destaquemos aquí a los integrantes del primer comité directivo de la Asociación Departamental: Profesores David Mujica Ortiz, Secretario General; Fortunato Zora Carvajal, Secretario de Interior y, Alicia Molina, Secretaria de Finanzas. En su comunicado de fundación expresa escuetamente: "La educación no depende del gobierno, ni de los maestros única y exclusivamente, sino es y será obra conjunta y abnegada de todos los peruanos". Seguidamente, en actitud de compromiso, aseguran:

... trabajaremos porque el maestro mejore social y económicamente, así como porque los poderes públicos $y$ los padres de familia, les concedan de hoy en adelante al educador del niño, preferencial atención con el fin de que amase en mejores condiciones al ciudadano de los tiempos nuevos. (La Nación 9 de julio de 1931).

Por su parte empleados particulares de diferentes casas comerciales deciden agruparse para fundar el "Sindicato de Empleados de Comercio, Banca e Industria de Tacna, el 26 de agosto de 1931. En esa época el pequeño número de empleados por cada casa o empresa comercial (menos de 20) no posibilitaba la formación de sindicatos por empresa. El censo del 22 de julio de 1935 realizado en la ciudad de Tacna confirma lo aseverado, con la advertencia de que las casas comerciales, bodegas y pulperías concentran un mayor número de servidores por el número de las mismas. 
Tabla 4

OCUPACIÓN DE LA POBLACIÓN MAYOR DE 14 AÑOS EN CASAS COMERCIALES DE TACNA.

\begin{tabular}{lccr}
\hline \multicolumn{1}{c}{ Ocupación } & Hombres & Mujeres & Total \\
\hline Bancos & 10 & 1 & 11 \\
Casas de seguros & 1 & - & 1 \\
Pastelerías y dulcerías & 12 & - & 12 \\
Casas de comercio may/min & 86 & 19 & 105 \\
Farmacias & 7 & - & 7 \\
Hoteles, cafés, etc. & 14 & 3 & 17 \\
Bodegas, pulperías & 42 & 13 & 55 \\
Aguas gascosas & 10 & - & 10 \\
Velas & 5 & 1 & 6 \\
Panaderías & 12 & - & 12 \\
Imprentas & 15 & - & 15 \\
Empresas de espectáculos & 6 & - & 6 \\
\hline
\end{tabular}

Fuente. Censo de población de Tacna-Calana-Pachía. 1935.

La primera junta directiva del Sindicato de Empleados fue constituida por Arturo Valdivia, Secretario General; Donato Gonzales, Secretario de Organización; Guillermo del Piélago G., Secretario de Economía; José Claudio Humire, Secretario de Actas; Manuel Oviedo Ch., Secretario de Propaganda. En su Plan de Acción, sostiene: "El Sindicato de Empleados de Comercio (...) es una organización de clase que tiende a agrupar en su seno a todos los trabajadores de esta categoría, sin exclusivismos sociales, políticos y religiosos" (La Nación, 17 de setiembre de 1931).

Los activistas apristas promocionaron la formación de sindicatos de agricultores en los valles de Tacna y Sama; igualmente sindicatos de choferes, sastres, carpinteros y pintores, los que en buena cuenta fueron asociaciones de pequeños propietarios y trabajadores independientes.

La estructura productiva incipiente no posibilitó el desarrollo de las organizaciones sindicales en el departamento, menos aún con los tempranos antagonismos apristas desde el sector magisterial y socialistas desde el sector comercial. El contexto de guerra civil sumado a la crisis económica en el país jugó en contra de la centralización del movimiento. La Confederación General de Trabajadores del Perú (CGTP) que estaba en ascenso, fue desarticulada por el gobierno de Sánchez Cerro con la aplicación de la Ley de Emergencia. Similar destino siguió la Federación Nacional de Maestros, fundada en 1931. Los planteamientos reivindicacionistas de los gremios tacneños quedaron postergados, entre otros: el reconocimiento de las indemnizaciones, reconocimiento del tiempo de servicios para ascensos y aumentos progresivos, supresión de empleados a prueba, fijación de sueldos mínimos para principiantes durante los tres primeros meses, seguro social extensivo a todos los trabajadores.

\section{IV \\ POLÍTICA EDUCATIVA Y NUEVA EDUCACIÓN}

Las primeras acciones de política educativa del régimen en Tacna reincorporada se realizaron en el marco de la Constitución política y del Reglamento de Instrucción vigentes. El gobierno expidió las resoluciones supremas $\mathrm{N}^{\circ} 1767 \mathrm{y}$ 1768 de fecha 20 de julio de 1929 , por las que se autorizó "los gastos necesarios para el establecimiento del sistema escolar nacional en la provincia de Tacna reincorporada a la nacionalidad". Mediante resoluciones directorales de fecha 3 de agosto del mismo año, se procedió a encargar provisionalmente las direcciones de los colegios nacionales de mujeres y de varones, así como la conducción de la Inspección de Enseñanza de Tacna. En estos dos últimos casos la comisión recayó en el Dr. Guillermo Rosemberg, Inspector de enseñanza oficial de Lima.

Del mismo modo, por resolución directoral del 19 de agosto, en cumplimiento de la Resolución Suprema N 1767 que aprobó el Presupuesto administrativo, se procedió al nombramiento de los directores y profesores de las escuelas primarias de la provincia. Igualmente por resoluciones directorales del 19 de agosto, en cumplimiento de la Resolución Suprema $\mathrm{N}^{\circ} 1768$ se efectuó el nombramiento del personal docente, administrativo y auxiliar de los dos colegios nacionales con sede en la ciudad de Tacna. 
Tabla 5

TOTAL DE ESCUELAS DE PRIMERA ENSEÑANZA DE LA PROVINCIA DE TACNA AL MOMENTO DE SU REINCORPORACIÓN.

\begin{tabular}{llccc}
\hline Localidad/Escuela & Varones & Mujeres & Mixtas & Total \\
\hline Tacna & $\mathbf{3}$ & 2 & - & $\mathbf{5}$ \\
Pocollay & 1 & $\mathbf{1}$ & - & 2 \\
Para & - & - & 1 & 1 \\
Calana & - & - & 1 & 1 \\
Pachía & 1 & $\mathbf{1}$ & - & 2 \\
Calientes & - & - & 1 & 1 \\
Total & $\mathbf{5}$ & $\mathbf{4}$ & $\mathbf{3}$ & $\mathbf{1 2}$ \\
\hline
\end{tabular}

Fuente. Ministerio de Instrucción. Boletín de enseñanza, julio y agosto de 1929.

En suma, lo que hizo el gobierno central fue restablecer el sistema educativo en Tacna en el marco de una política educativa nacional modernizante y asistencialista, la cual comprendió: dotación de material didáctico para las escuelas estatales; incremento de bibliotecas escolares; provisión de cargos dentro del escalafón magisterial mediante un sistema de concurso; beneficios de la ley de cesantía, jubilación y montepío para el personal docente; formación profesional de profesores de educación secundaria. Se estableció el desayuno escolar, se impulsó la educación para el trabajo creando escuelas técnicas y se otorgó becas de estudios para los estudiantes de los estratos más pobres.

Paralelamente a la implementación oficial de la educación, llegaron las nuevas corrientes pedagógicas que la prensa local se encargó de difundir. Profesores de los centros educativos de Tacna (Zora Carvajal, Mujica, Urrutia y Canturín) impulsaron la opción de la escuela única estatal y la propuesta de una reforma educativa como parte de las innovaciones de la corriente Escuela Nueva. El diario La nación acogió sus artículos reformistas, también dio curso a la publicación de colaboraciones externas, entre ellas las del francés Paul Fauconnet y el suizo Pierre Bovet. Por su parte el diario El Caplina divulgó el pensamiento de la educadora peruana Elvira García y García respecto a la escuela activa.

Al promediar diciembre de 1931, cuando se exacerbaban las contradicciones entre la tendencia fascistizante en el gobierno y la oposición aprista de la socialdemocracia radicalizada, el profesor normalista Félix Canturín, del Colegio Nacional de Varones, escribía para el diario La Nación sus Tres puntos de vista sobre educación en Tacna; lo que en esencia era la puesta en relieve de tres factores condicionantes del desarrollo de la educación de ayer y de todos los tiempos, en países atrasados, emergentes y sujetos a dependencias como el nuestro. Por ese entonces el educador apuntaba: "La influencia extranjera, el factor maestro y el factor económico son tres motivos que han contribuido a la detención de la obra de la educación en Tacna". Obviamente se refería a los casi cincuenta años bajo administración chilena, así como a los años iniciales del civilismo y últimos del oncenio leguiista, que en conjunto implementaron una educación adecuada a las necesidades de una economía capitalista en formación, bajo el modelo primario exportador, lo que básicamente resultaba favorable a los intereses extranacionales. El educador de la coyuntura, recogiendo el sentir generacional por una educación nacionalista y popular con profesionales competentes y comprometidos socialmente, reclamaba para Tacna de los años 30 una escuela normal mixta, escuela vocacional, granja-escuela y escuelas rurales ambulantes en cada valle, para cuya realización, expresaba: "el factor económico resulta su eje motor", lo que es evidente. Una educación innovada y para el cambio, sin el financiamiento suficiente, oportuno y sostenido, está destinada al fracaso. Pero el educador Canturín sostenía también, con la firmeza de los promotores de la escuela nueva, que "la misión del maestro (...) no está simplemente en instruir, sino en educar efectiva y realmente y preparar para un futuro muy próximo", expresiones certeras y trascendentes que ahora las hacen suyas los constructivistas y demás innovadores de la educación.

Debemos precisar que la Escuela nueva (denominada también escuela activa, nueva educación, educación nueva, educación para el trabajo) surgió y se desarrolló en Europa y Estados 
Unidos de los siglos XIX y XX, al influjo del avance científico-tecnológico y las necesidades de consolidación de las sociedades capitalistas en su fase industrial; planteó innovaciones doctrinarias y metodológicas para formar al hombre del futuro, teniendo por eje el principio "aprender haciendo" en un ambiente de libertad $\mathrm{y}$ de respeto a la individualidad. Esta propuesta, si se quiere universal, fue saludada y recibida con elevado interés por quienes en el planeta, aspirantes a la modernidad y el cambio, empezaban a tomar distancia de la escuela tradicional por autoritaria, discursiva, enciclopédica, memorística y conservadora.

Promotores representativos de la Escuela Nueva en el Perú fueron Carlos Salazar Romero y José Antonio Encinas; el primero, con mentalidad liberal modernizante, centró su atención en las innovaciones pedagógicas colaborando con las políticas de los sucesivos gobiernos liberales; el segundo, con mentalidad de avanzada socialdemócrata, abogó por una escuela laica y del trabajo, sosteniendo que “...una escuela del trabajo se asfixiaría en el Perú, si antes o simultáneamente no se resuelve los problemas de orden social y agrario". Así con estos antecedentes, más los relativos a la orientación ideológica y pedagógica de los autores de los artículos educativos de la coyuntura, podemos distinguir: una Escuela Nueva Liberal para modernizar el sistema asegurando su continuidad, y otra Escuela Nueva Alternativa para contribuir al cambio del sistema mediante una revolución social.

La dura confrontación de la socialdemocracia con la reacción civilista-liberal-fascistizante frustró la propuesta alternativa. Los años 19321934 serán de la propuesta de la Escuela Nueva
Liberal. En Tacna, la prensa fascistizante (La Verdad) llama a la defensa del orden establecido; las autoridades educativas y políticas coordinan estrechamente; el Colegio Nacional de Varones será el centro de los primeros ensayos de la Escuela Nueva Liberal con su director el Dr. Gonzalo Bravo Mejía, ferviente admirador del pensamiento de Decroly y Dewey, de quienes decía: "son pragmáticos, dinámicos y predican la escuela de la acción". Bravo Mejía emprendió una reforma educativa aplicando el método decrolyano en primaria y la "escuela por la acción" en secundaria. La prensa difundió su labor a la vez que publicó artículos pedagógicos sobre métodos, activos, disciplina, cultivo de las emociones y relaciones en la escuela.

En concreto, la reforma de la Escuela Nueva Liberal pretendió una educación secundaria con cuatro años de cultura general y dos de formación técnico-profesional en las áreas industrial, comercial ganadera, agrícola y artística, en el supuesto de servir o atender a los requerimientos del sistema social. Sin embargo esta reforma no tendría el éxito deseado por no estar ligada a otras reformas de orden social y económico, como así lo pretendió la propuesta de la Escuela NuevaAlternativa.

\section{V \\ MODERNIDAD Y MODERNIZACIÓN EN LA COYUNTURA}

En Tacna que se reincorpora y anhela con justicia las reivindicaciones que su identidad nacional amerita, nos interesa centrar la atención en los indicadores de su modernidad y modernización; porque ellos nos permiten comprender la actitud de progreso de los individuos y grupos componentes de la sociedad tacneña, su concepción del mismo y su práctica social. 
Tabla 6

ÓRGANOS DE PRENSA ESCRITA DE TACNA EN LA COYUNTURA 1929-1934.

\begin{tabular}{llllll}
\hline \multirow{2}{*}{$\begin{array}{l}\text { Organos de } \\
\text { Prensa }\end{array}$} & $\begin{array}{l}\text { Afio de } \\
\text { publicación }\end{array}$ & $\begin{array}{l}\text { Frecuencia de } \\
\text { edición }\end{array}$ & \multicolumn{3}{c}{ Observaciones } \\
\cline { 4 - 6 } & & & Node pág $^{\circ}$ & Dimen. Cm & Tendencia \\
\hline La Patria & 1929 & Bisemanario & 4 p.s.f.** & $27.0 \times 38.2$ & Liberal \\
La Opinión & $1929-1930$ & Diario & 6 p.f.*** & $36.5 \times 53.5$ & $\&$ \\
La Nación & $1930-1932$ & Diario & 4 p.f. & $36.5 \times 53.5$ & Socialdem \\
El Tacora & $1930-1932$ & Diario & 4 p.f. & $36.0 \times 50.0$ & Liberal \\
La Verdad & $1932-1934$ & Diario & 4 p.f. & $37.0 \times 53.3$ & Fascistizan \\
El Deporte Tacneño & 1932 & Semanario & 6 p.f. & $25.5 \times 36.5$ & $\&$ \\
Justicia & $1933-1934$ & Bisemanario & 6 p s.f. & $24.5 \times 36.0$ & Aprista \\
La Voz del Sur & 1934 & S-B-I-D* & 8 p.f. & $27.5 \times 38.5$ & Liberal \\
EL Caplina & 1934 & Diario & 4 p.f. & $37.0 \times 53.3$ & liberal \\
El Suplemento & 1934 & Semanario & 4 p.s.f. & $39.0 \times 55.0$ & $\&$ \\
LaVozdelDepartamento & 1934 & Eventual & 4 p.s.f. & $32.0 \times 47.0$ & $\&$ \\
& & & & &
\end{tabular}

\footnotetext{
*Primero semanario, después bisemanario, interdiario y diario.

**Páginas sin foliar.

***Páginas foliadas. \& Contemporizadora.

Fuente. Archivo Regional. Elaboración del autor (ART. E del a.).
}

Tomaremos a las tendencias periodísticas liberal y fascistizante como indicadores de una modernidad con innovaciones para mantener la continuidad del sistema social; la tendencia socialdemócrata por una modernidad con un pretendido cambio estructural del sistema social y, la tendencia contemporizadora, aparentemente ausente del debate sobre la modernidad, pero terminando por condescender con el régimen establecido. Los periódicos que circularon en la coyuntura 1929-1934 han registrado la incidencia de tales tendencias en el desarrollo de la modernidad en Tacna.

Cronológicamente, en el grupo de prensa diaria se ubica a La Opinión como el primer diario de la coyuntura que se publicó entre noviembre de 1929 y marzo de 1930 , en total 4 meses de circulación. Sigue La Nación, importante diario de la coyuntura que se publicó entre agosto de 1930 y febrero de 1932, en total 18 meses. Paralelamente surgió El Tacora, entre octubre de 1930 y febrero de 1932, en total 16 meses. El diario de más duración fue La Verdad, que se publicó entre febrero de 1932 y mayo de 1934, en total 27 meses. La Verdad sustituyó a La Nación en momentos cuando en el Perú se agudizaban las contradicciones político-sociales, con el correspondiente cierre de los periódicos de oposición y de aquellos que eventualmente perdían la gracia del régimen fascistizante. La Nación y El Tacora fueron cerrados en febrero de 1932, luego del apresamiento y tácito desaforo de 27 congresistas constituyentes, entre ellos
Juan Arce Arnao quien fuera director de La Nación. Por último el diario El Caplina publicado desde el 2 de junio de 1934 y durante todo el segundo semestre de ese año, en total 7 meses de circulación periodística regular. En realidad, El Caplina fue el relanzamiento de La Verdad, cuya existencia llegó hasta 1936, año en que fue sustituido por La Voz de Tacna.

La prensa no diaria fue de existencia corta y de frecuencia irregular. En el momento de la Reincorporación de Tacna se editó La Patria, Bisemanario Noticioso e Informativo como rezaba su subtítulo. La Nación al celebrar su primer aniversario dio cuenta de este bisemanario, seguido de los periódicos La Opinión, La Voz de Tacna y La Concordia (estos dos últimos no aparecen en la muestra). La prensa no diaria más representativa, por su frecuencia de edición fue Justicia, con el subtítulo Bisemanario aprista: apareció en setiembre de 1933, cuando el gobierno del general Benavides practicaba la política de "paz y concordia", como un intento por superar, según se decía, la grave crisis político-social en que se debatía el país. Justicia tuvo la duración de un año. Paralelamente se publicaron, en 1934, los periódicos La Voz del Sur, EI Suplemento y La Voz del Departamento, con ediciones irregulares.

En cuanto a las tendencias periodísticas, destacamos la contemporizadora que signó la práctica periodística del diario La Opinión: una conducta que osciló entre un supuesto neutralismo, 
la independencia, la expectativa y la condescendencia respecto al oncenio leguiista; tendencia con la que se identificó la prensa no diaria conformada por El Deporte Tacneño, durante el gobierno de Sánchez Cerro en 1932, La Voz del Departamento y El Suplemento, durante el gobierno de Benavides en 1934. La tendencia contemporizadora estuvo ausente en la formación de la conciencia social. La prensa que asumió esa tendencia fue la que cubrió su impotencia con el disfraz de la neutralidad ante los gobiernos centralistas y antidemocráticos. La Nación en la nota editorial de su primer aniversario, al referirse a La Opinión y otras publicaciones de la coyuntura, expresa que su práctica periodística fue "con voz amordazada por el oncenio".

La tendencia liberal estuvo representada inicialmente por el bisemanario La Patria en 1929, en el último tramo del oncenio leguiista, régimen al cual reconoció por el logro de la Reincorporación de Tacna. Después, entre 1930 y 1932, se edita el Tacora con el entusiasmo de sus promotores nacionalistas y patrióticos; no obstante, su escasa capacidad de empresa manifiesta en sus ediciones discontinuas y su endeble línea editorial y carencia de artículos de opinión limitaron su gravitación en la coyuntura, por lo que optaron por una suerte de pragmatismo adaptativo itinerante que fue de Sánchez Cerro a Arturo Osores y de este al primero, probablemente urgidos por contrarrestar el avance socialdemócrata aprista promocionado por La Nación y Justicia.

Asimismo fue de tendencia liberal moderada La Voz del Sur en 1934, publicación eventual irregular. Se agrega el diario El Caplina que circuló en el segundo semestre del año 1934, apareciendo como un órgano oficioso del gobierno autoritario de Benavides, con antecedentes fascistizantes. Este diario se caracterizó por la publicación de noticias breves, con amplia cobertura a la promoción del comercio, lo que se ratifica con el subtítulo: "Diario de la mañana, noticioso, comercial y propagandístico del resurgimiento de Tacna".

La tendencia socialdemócrata fue mejor representada en La Nación que en Justicia. La Nación aparece como un diario con mayor calidad técnica y profesional en su estructura, en sus contenidos y en su función orientadora. La dirección de La Nación cuida de disponer de un porcentaje significativo de contenidos ideopolíticos para contribuir a la formación de la conciencia social y política en la perspectiva de la democratización del país. Asimismo cuida de la responsabilidad en la publicación de artículos de opinión, cuando advierte que no se admitirá artículos sin autoría. Por su parte Justicia, con su expresa filiación partidaria, tiene la consecuencia y coherencia en la publicación de los contenidos orientadores ideopolíticos, aunque no la calidad en su presentación.

La tendencia fascistizante junto con la socialdemócrata fueron las más influyentes en el ejercicio de la orientación ideopolítica; la primera buscó la modernización del Estado centralista en crisis; la segunda, la democratización con el cambio estructural. La tendencia fascistizante contó con el apoyo de los gobiernos de turno, asegurando una acción más prolongada; la tendencia socialdemócrata optó por el camino más difícil, el alternativo. Ambas cumplieron con la función orientadora de manera abierta y desde su particular perspectiva, pero la fascistizante, al igual que la liberal, fue afectada en la consistencia y calidad de función por el arrebato emocional.

Si convenimos que el periodismo tiene tres funciones básicas: Informar, distraer y orientar, entonces la frecuencia de edición de los periódicos diaria o no diaria, seguido de la duración corta o larga de sus publicaciones, constituyen indicadores de la disposición que tiene para ejercer esas funciones básicas sobre la colectividad. Así la prensa diaria, por sus entregas cotidianas y regulares, crea hábitos, alimenta y retroalimenta comportamientos, instituye ideas-fuerza. La prensa no diaria, distanciada en sus entregas por su condición de bisemanario, semanario o publicación eventual, más aún irregular por sus interrupciones, está seriamente limitada para cumplir con las funciones básicas de manera efectiva.(Panty 0.2001,p.51) 
La función de informar se cumple con la inclusión de artículos en el espacio diagramado de cada una de las páginas de los órganos de prensa escrita. Tales artículos proyectan contenidos noticiosos y contenidos publicitarios.

Tabla 7

DISTRIBUCIÓN PORCENTUAL DE LOS CONTENIDOS PERIODISTICOS EN EL ESPACIO DLAGRAMADO DE LA PRENSA ESCRITA 1929-1934.

\begin{tabular}{lllc}
\hline Órganos de Prensa & \multicolumn{2}{c}{ Contenidos } & Total \\
\cline { 2 - 3 } & Noticiosos\% & Publicitarios\% & \\
\hline La Patria & 44.00 & 56.00 & 100.00 \\
La Opinión & 49.00 & 51.00 & 100.00 \\
La Nación & 46.71 & 53.29 & 100.00 \\
El Tacora & 47.23 & 52.77 & 100.00 \\
La Verdad & 52.22 & 47.78 & 100.00 \\
El Deporte Tacneño & 91.67 & 8.33 & 100.00 \\
Justicia & 87.50 & 12.50 & 100.00 \\
La Voz del Sur & 77.34 & 22.66 & 100.00 \\
El Caplina & 60.46 & 39.54 & 100.00 \\
El Suplemento & 91.67 & 8.33 & 100.00 \\
La Voz del Departamento & 60.00 & 40.00 & 100.00 \\
\hline Total Promedio & 64.15 & 35.85 & 100.00 \\
\hline Fuen
\end{tabular}

Fuente. ART, E del a.

La muestra de los once periódicos de nuestro estudio presenta en la tabla 7 un porcentaje mayor de contenidos noticiosos $(64.15 \%)$, respecto a los contenidos publicitarios $(35.85 \%)$. Sin embargo, retomando la distinción prensa diaria y prensa no diaria, encontramos que la primera destina un porcentaje medio de su espacio diagramado para la publicidad, ascendente a $48 \%$. La segunda oscila entre los casos extremos de los semanarios El Deporte Tacneño y El Suplemento, cuyo porcentaje publicitario se reduce al $8 \%$, mientras que el bisemanario La Patria llega al 56\%.

El predominio de los contenidos informativos en la prensa de la coyuntura guarda relación con su naturaleza de empresa comercial, conse- cuentemente con la demanda de sus lectores. La prensa de ayer, como la de ahora, ha publicado en primer lugar lo que en sus cálculos de mercado estimó que sus lectores consumen; y, en segundo lugar, lo que pretendió habituar a que consumiesen, en tanto información de interés inmediato.

La prensa diaria, comercial e influyente en la coyuntura destinó un promedio de $48 \%$ del espacio diagramado a la publicidad, con lo que aseguró su existencia. La otra parte del espacio diagramado evidentemente mayor al $50 \%$ fue compartido por los tres tipos de contenidos noticiosos: Informativos, distractivos y orientadores.

Tabla 8

DISTRIBUCIÓN PORCENTUAL DE LOS TIPOS DE CONTENIDOS NOTICIOSOS EN LA PRENSA ESCRITA DE TACNA EN LA COYUNTURA 1929-1934.

\begin{tabular}{|c|c|c|c|c|}
\hline \multirow[t]{2}{*}{ Órganos de prensa } & \multicolumn{3}{|c|}{ Contenidos noticiosos } & \multirow{2}{*}{$\begin{array}{c}\text { Total } \\
\%\end{array}$} \\
\hline & Informativo & Distractivo & Orientador & \\
\hline La Patria & 88.00 & - & 12.00 & 100.00 \\
\hline La Opinión & 83.40 & - & 16.60 & 100.00 \\
\hline La Nación & 72.20 & 9.80 & 18.00 & 100.00 \\
\hline El Tacora & 84.72 & 1.39 & 13.89 & 100.00 \\
\hline La Verdad & 79.15 & 11.75 & 9.10 & 100.00 \\
\hline El Deporte Tacneño & 90.91 & 9.09 & - & 100.00 \\
\hline Justicia & 47.62 & 19.04 & 33.34 & 100.00 \\
\hline La Voz del Sur & 72.00 & 9.67 & 18.33 & 100.00 \\
\hline El Caplina & 64.29 & 21.42 & 14.29 & 100.00 \\
\hline El Suplemento & 68.19 & 18.18 & 13.63 & 100.00 \\
\hline La Voz del Departamento & 74.16 & 4.16 & 21.68 & 100.00 \\
\hline Tota 1 & 74. & & 15. & $\mathbf{1 0 0 . 0 0}$ \\
\hline
\end{tabular}

Fuente. ART. E del a. 
Según la tabla 8 , los contenidos informativos contaron con una mayor participación que el espacio diagramado porque así convenía al diario comercial. Vale decir el diario comercial aseguraba su existencia vendiendo no solo parte del espacio diagramado para la publicidad, sino también vendiendo información de interés general e inmediato para los lectores habituales o por habituar. Los otros contenidos distractores y orientadores fueron relativamente vendibles, o simplemente agregados como motivos culturales en el espacio diagramado.

Sin embargo es evidente que los contenidos orientadores, como las propuestas de descentralismo o de desarrollo industrial en el marco de una política de fronteras, tuvieron - y tienen en todas las épocas - importancia social por sus ideas-fuerza generadoras de conductas colectivas y movimientos sociales, obviamente en relación a ciertos movimientos coyunturales y a la tendencia idepolítica del periódico, dentro de los márgenes de autonomía y tolerancia permitidos por la publicidad o por los dueños de los objetos de publicidad.
De un total de 759 artículos registrados en la muestra periodística de la tabla 9, el mayor porcentaje de contenidos corresponde al tipo ideopolíticos $29.91 \%$, seguido por los contenidos cívico patrióticos $24.30 \%$ y económicos $24.37 \%$. Los contenidos educativos, estrictamente formales, alcanzan a $11.3 \%$. En este contexto, los diarios La Nación, La Verdad y El Caplina destacan por la mayor cabida que dieron en sus páginas a los contenidos orientadores con $39.13 \%, 38.74 \%$ y $13.59 \%$, respectivamente. Específicamente, La Nación (diario socialdemócrata), frente al proceso electoral de 1931, promociona contenidos cívico-patrióticos $14.36 \%$, ideológicos $12.25 \%$ y económicos $7.51 \%$; La Verdad (diario facistizante), frente a la coyuntura en general, con los contenidos económicos $12.39 \%$ ideopolíticos $8.17 \%$, seguido de los educativos y cívico-patrióticos $5.93 \%$ y $5.53 \%$; El Caplina (diario liberal), durante el frustrado proceso electoral de 1934, en el lapso de siete meses de circulación con los contenidos ideopolíticos $5.54 \%$, económicos $3.43 \%$ y cívico-patrióticos $2.51 \%$.

Tabla 9

TIPOS DE CONTENIDOS ORIENTADORES PUBLICADOS EN LA PRENSA ESCRITA DE TACNA EN LA COYUNTURA 1929-1934.

\begin{tabular}{|c|c|c|c|c|c|c|c|}
\hline \multirow[t]{2}{*}{ Órganos de prensa } & \multicolumn{5}{|c|}{ Contenidos orientadores } & \multicolumn{2}{|r|}{ Total } \\
\hline & Total & $\begin{array}{l}\text { Ideopol } \\
\%\end{array}$ & $\begin{array}{l}\text { Econó } \\
\%\end{array}$ & $\begin{array}{l}\text { Civi-pat } \\
\%\end{array}$ & $\begin{array}{l}\text { Educat } \\
\%\end{array}$ & $\begin{array}{l}\text { Otros } \\
\%\end{array}$ & $\%$ \\
\hline La Patria & 2 & 0.13 & - & 0.13 & - & - & 0.26 \\
\hline La Opinión & 2 & - & - & 0.13 & 0.13 & - & 0.26 \\
\hline La Nación & 297 & 12.25 & 7.51 & 14.36 & 3.43 & 1.58 & 39.13 \\
\hline El Tacora & 9 & 0.40 & 0.26 & 0.40 & 0.13 & - & 1.19 \\
\hline La Verdad & 204 & 8.17 & 12.39 & 5.53 & 5.93 & 6.72 & 38.74 \\
\hline El Deporte Tacneño & - & - & - & - & - & - & - \\
\hline Justicia & 35 & 2.77 & 0.26 & 0.92 & 0.13 & 0.53 & 4.61 \\
\hline La Voz del Sur & 9 & 0.26 & 0.26 & 0.26 & 0.13 & 0.27 & 1.18 \\
\hline EL Caplina & 103 & 5.54 & 3.43 & 2.51 & 1.32 & 0.79 & 13.59 \\
\hline La Voz del Departamento & 4 & 0.13 & 0.13 & 0.26 & - & - & 0.52 \\
\hline El Suplemento & 4 & 0.26 & 0.13 & - & 0.13 & - & 0.52 \\
\hline Total Promedio & 759 & 29.91 & 24.37 & 24.50 & 11.33 & 9.89 & 100.00 \\
\hline
\end{tabular}

Fuente. ART. E del a.

Es básico señalar que aun cuando en los periódicos no se encuentran artículos orientadores, como se observa en algunas ediciones de la muestra periodística, los artículos estrictamente denominados informativos (para algunos, información neutral), también tienen una dosis de orientación, una orientación oculta; puesto que son elaborados por seres humanos social- mente condicionados en el marco de una realidad concreta. De aquí nuestra afirmación que, incluso sin el porcentaje mínimo de orientación, en medio de la aparente neutralidad, toda información tiene una orientación intencional que se proyecta a la búsqueda de una respuesta, a estimular una conducta o a generar una actitud. 
Tabla 10

ARTÍCULOS-PROPUESTA DE LA PRENSA TACNEÑA POR AREAS DE DESARROLLO ECONÓMICO SEGÚN TENDENCIAS IDEOLÓGICAS 1929-1934.

\begin{tabular}{|c|c|c|c|c|c|}
\hline \multirow{3}{*}{$\begin{array}{l}\text { Áreas de } \\
\text { Desarrollo } \\
\text { económico }\end{array}$} & \multirow{2}{*}{$\begin{array}{l}\text { Total de } \\
\text { artículos }\end{array}$} & \multicolumn{3}{|c|}{ Tendencias } & \multirow[b]{2}{*}{ Total } \\
\hline & & Liberal & Socialdemócrata & Sin clasificar & \\
\hline & $\%$ & $\%$ & $\%$ & $\%$ & $\%$ \\
\hline Agricultura & 38 & 32.72 & 1.82 & - & 34.54 \\
\hline Infraestruc. vial & 27 & - & - & 24.55 & 24.55 \\
\hline Comercio & 26 & 23.64 & - & - & 23.64 \\
\hline Minería & 8 & 7.27 & - & - & 7.27 \\
\hline Finanzas & 7 & 3.64 & 2.72 & - & 6.36 \\
\hline Industria & 4 & 3.64 & - & - & 3.64 \\
\hline Total & 110 & 70.91 & 4.54 & 24.55 & 100.00 \\
\hline
\end{tabular}

Fuente. ART. E del a.

En la tabla 10 se presenta un registro porcentual de artículos-propuesta para el desarrollo regional que la prensa tacneña canaliza por áreas de desarrollo económico y según tendencias de política económica de la coyuntura. Se entiende que la tendencia liberal pretende la modernización de las áreas de un capitalismo incipiente que la administración chilena no pudo resolver, empezando por la agricultura y la infraestructura vial; por su parte la tendencia socialdemócrata pretende la progresiva intervención del Estado como ente promotor de la economía, además de las soluciones mixtas con la co-participación Estado-empresa privada.

Una observación de conjunto nos revela a la tendencia liberal canalizando el mayor porcentaje de los artículos-propuesta en todas las áreas, llegando al $70.91 \%$. Con dicha tendencia, las propuestas, en orden descendente, inciden en la promoción de la agricultura con $32.72 \%$, comercio con $23.74 \%$, minería con $7.7 \%$, seguido de finanzas e industria con $3.64 \%$. Por otra parte la tendencia de la solución socialdemócrata totaliza agricultura con finanzas en $4.54 \%$. Se advierte que el área de infraestructura vial concentra el $24.55 \%$ de artículospropuesta, los que por su naturaleza, al margen de la ideología, no se clasifica en tendencia alguna. Pero la infraestructura vial (carreteras, líneas férreas, puertos) es fundamental, vital, para todo programa de desarrollo.

Históricamente, desde los inicios de la república, el modelo de desarrollo económico en el Perú viene siendo liberal. Este modelo ha significado, para nosotros, la modernización de la economía, manteniendo desigualdades, jerarquías y exclusiones en lo económico y social, y la dependencia a grupos de poder internacional.

Tacna reincorporada en 1929, se asimiló al modelo liberal en crisis, agravada luego por la gran crisis internacional. Las propuestas estatales y de soluciones intermedias alcanzadas por la socialdemocracia aprista-y la tendencia descentralista en el país- no se llegaron a concretar en tanto ese movimiento vertebrado como partido no llegó al poder con las elecciones de 1931, y más bien fue objeto de la más dura represión por el régimen fascistizante de Sánchez Cerro y Benavides. De allí que en Tacna de la coyuntura primaran las propuestas económicas de la tendencia fascistizante, aunque sus resultados finalmente fueron ínfimos por la escalada de la crisis internacional. Ni el gobierno nacional estuvo en la capacidad de atender la materialización de las propuestas en referencia, por la reducción de sus presupuestos y su tendencia centralista, ni en modo alguno la iniciativa privada — particularmente la local— hondamente deprimida y más sumida en lo comercial.

\section{CONCLUSIONES}

1. Al momento de la Reincorporación de Tacna en 1929, la sociedad peruana en general presentaba un desarrollo desigual y combinado. En su base económica persistían las formas precapitalistas, particularmente en el agro andino; contrariamente se proyectaba la modernización capitalista en el agro costeño, en la explotación minero petrolera y en el comercio, dentro de los parámetros del modelo económico primario exportador sujeto a los dictados del gran capital imperialista norteamericano. 
2. La Reincorporación de Tacna fue gestionada con la promesa de su reivindicación en mérito a la fortaleza de su identidad nacional; aunque, en oposición a lo esperado, resultó significando la continuidad de la situación deprimente vivida por este pueblo durante cincuenta años bajo administración chilena. El Estado peruano se reprodujo en Tacna restableciendo la demarcación departamental con sus instituciones y autoridades en sus diversas instancias; no obstante, los órganos sectoriales estuvieron limitados en sus funciones, decisiones e iniciativas, por la fuerte dependencia del gobierno central respecto a la reducida disponibilidad de recursos presupuestales, la carencia de personal calificado y la falta de coordinación intersectorial.

3. La crisis económica en Tacna, durante la coyuntura de 1929-1934, tuvo sus primeras manifestaciones en el no cumplimiento gubernamental de las obras ofrecidas desde Lima por el presidente Leguía, en acto público simultáneo al de la "firma de la entrega de Tacna". El Estado centralista (representado sucesivamente por los gobiernos de Leguía-Sánchez CerroBenavides) estuvo sumamente reducido en la captación de ingresos físcales con su modelo primario exportador, por cuanto la crisis disminuyó drásticamente los precios de los productos mineros y agrícolas en el mercado internacional; en consecuencia, no pudo cumplir con sus promesas y obligaciones de la reivindicación de Tacna. El presupuesto de la república descendió de 50 millones de dólares en 1929, a 16 millones de dólares en 1932, el año más difícil. En Tacna, "sin industrias de importancia" (solo gaseosas, fideos y velas), la incipiente agricultura redujo sus volúmenes de exportación de productos de pan llevar en $50 \%$, generando a su vez la desocupación rural. Tacna fue postergada por largos años, rebasando la coyuntura.

4. Durante la coyuntura de 1929-1934, surgieron y se potenciaron tres tendencias ideológicas de importancia nacional: La socialdemocracia en la versión del partido aprista, principal organización de masas que sostenía una prédica antioligárquica y antiimperialista, levantando un programa de reformas de la sociedad y el Estado. El socialismo mariateguista, inspirado en el marxismo-leninismo ortodoxo, que anunció una transformación nacional rechazando y combatiendo al protagonismo de la socialdemocracia "en todas sus formas, métodos y tendencias". El nacionalismo fascistizante del partido Unión Revolucionaria que respondió a los intereses del gamonalismo y la plutocracia, consecuentemente su propósito inmediato fue restablecer y mantener el orden frente a la crisis y la beligerancia política.

Las tendencias ideológicas socialdemocracia y socialista tuvieron una relativa influencia en los sectores laborales. La socialdemocracia propició entre los profesores de Tacna la primera Asociación de maestros; asimismo - no obstante la incipiente estructura productiva- la socialdemocracia estimuló la organización sindical de los choferes, carpinteros, sastres y agricultores. El socialismo mariateguista incidió en la formación del primer Sindicato de Empleados de Comercio, Banca e Industria de Tacna; mientras que la fracción comerciante, de ascendencia italiana, se alineó con la reacción fascistizante.

Frente a la corriente pedagógica Escuela Nueva propiciada en Europa y Norteamérica por los agentes del capitalismo industrial, en la perspectiva de su desarrollo hegemónico y la dependencia de nuestros países a sus intereses, la socialdemocracia en la coyuntura contribuyó a la propuesta de una escuela nueva alternativa para el desarrollo económico-social autónomo, soberano y con democracia. La dura confrontación de la socialdemocracia con la reacción fascistizante frustró la propuesta alternativa.

5. Los indicadores de modernidad y modernización de Tacna, en la coyuntura de 1929 y 1934, se expresan por medio de cuatro tendencias periodísticas en la prensa escrita: La tendencia liberal que se proyectó por toda la extensión de la coyuntura con un ejercicio periodístico discontinuo, una endeble línea editorial y la carencia de artículos de opinión, por lo que a su vez derivó sus propuestas de innovaciones en la línea de la continuidad del sistema económicosocial republicano; la tendencia contemporizadora, también presente en la coyuntura, con una práctica periodística informativa-distractiva $\mathrm{y}$ discontinua, en actitud de supuesta neutralidad e independencia frente a la confrontación del 
régimen en crisis con las alternativas ideológicas; la tendencia socialdemócrata por una modernidad con una propuesta de cambio estructural del sistema económico-social; la tendencia fascistizante, copartícipe de la modernidad del sistema económico-social capitalista, pero demandando la autoridad del Estado para el rechazo de las propuestas de modernidad y modernización con orientación socialdemócrata y socialista.

Las tendencias periodísticas fascistizante $y$ socialdemócrata fueron las más influyentes con sus propuestas de modernidad y modernización. La tendencia fascistizante contó con el apoyo de los gobiernos de turno, asegurando una acción más prolongada; la tendencia socialdemócrata optó por el camino más difícil, el alternativo. Ambas tendencias cumplieron con la función orientadora de manera abierta y desde su particular perspectiva; sin embargo, la escalada de la crisis internacional postergó las propuestas de modernidad y modernización más allá de la coyuntura.

\section{REFERENCIAS BIBLIOGRÁFICAS}

Basadre, Jorge (2000). Historia de la Repúbli ca del Perú. Octava edición corregida y aumentada. La República. Lima.

Cotler, Julio (1978). Clases, Estado y Nación en el Perú. IEP. Lima.

Haya de la Torre, Víctor Raúl (1986). El Antiimperialismo y el Apra. Ed. Lydea. Lima.

Mariátegui, José Carlos (1975). Ideología y Política. Edit. Amauta. Lima.

Panty Neyra, Oscar (2001). Función orientadora en la prensa escrita. Ed. Educa. Tacna.

Perú. Archivo Regional Tacna. Colección de periódicos de Tacna 1929-1934.

Boletín de enseñanza, julio y agosto de 1929. Ministerio de Instrucción.

Documentos: Matrícula de contribución comerciale industrial de Tacna. 1932.

Censo de población de Tacna-Calana-Pachía, 1935. Prefectura de Tacna. 